\title{
A Comparative Review on Different Trophic Modes and Usable Carbon Sources for Microalgae Cultivation, Approaching to Optimize Lipid Production in Trade Scale
}

\author{
Zahra Lari, Fatemeh Khosravitabar \\ Department of Biology, Faculty of Science, Ferdowsi University of Mashhad, Mashhad, Iran \\ E-mail: fa.khosravitabar@mail.um.ac.ir
}

Received: 29 February 2020; Revised: 27 April 2020; Accepted: 27 April 2020

\begin{abstract}
Microalgae are considered as an outstanding feedstock to produce high value lipid products like biodiesel and biomedicine. Reaching commercial maturity in this field is possible in the case of maximizing lipid yield and minimizing prime costs. In order to clarify the best features of carbon source (for microalgae cultivation) to reach optimum efficiency of biomass and lipid production, this paper reviews the merits and demerits of different trophic modes as well as type and concentration of carbon source. Furthermore carbon supplementation for large scale microalgae cultivation and lipid production is discussed as an economical point of view.
\end{abstract}

Keywords: microalgae, biomass, lipid, trophic modes, carbon source

\section{Introduction}

The importance of lipid nutritional supplements has been considered from many years ago, when some products like fish oils and shark liver oil were highly consumed as beneficial supplements [1]. Concurrent with developing lipid production through oil corns, lipids were regarded in terms of cosmetic applications [2]. Afterward, significance of lipids for biodiesel production, and also their value in the field of pharmaceutical advances (such as drug delivery process) attracted much consideration [3]. Fatty acids composition of lipids specifies the application of extracted lipids. For example, polyunsaturated fatty acids (PUFAs) are such as omega-3 fatty acids are interested as high-value products nutraceuticals and pharmaceutical industry [4], while neutral lipids, monounsaturated and saturated fatty acids (MUFAs \& SFAs) are preferred for biodiesel production [5-6].

Many scientific reports have described advantages of utilizing microalgae for lipid production over the other available feedstocks, which are briefly listed below:

(1) Microalgae have a really short simple life cycle and non-seasonal growth. (2) They don't need arable land for cultivation [7]. (3) Practically microalgae give us much higher growth rate and productivity (per hectare) as compared with higher plants [8]. (4) Different microalgae species can be adapted to survive in a variety of environmental conditions [9]. (5) Depending on applied species and cultivation conditions, a wide variety of lipid profiles, for different purposes, could be achievable from microalgae cultures [10]. (6) Microalgal biodiesel while contains no sulfur, can perform as great as petroleum diesel [11]. (7) Microalgae could be a suitable feedstock, not only for lipid production, but also for producing some other valuable products such as methane, ethanol and hydrogen [12]. (8) After oil extraction,

Copyright (C2020 Fatemeh Khosravitabar, et al.

DOI: https://doi.org/10.37256/sbe.112021293

This is an open-access article distributed under a CC BY license

(Creative Commons Attribution 4.0 International License)

https://creativecommons.org/licenses/by/4.0/ 
the residual biomass can be processed to organic fertilizer [13] and also livestock feed because of possessing a high N/ $\mathrm{P}$ ratio [14]. With consideration to all mentioned merits, microalgae could potentially revolutionize lipid production industry. However, despite many researches and developments in this field, microalgal lipid production has not reached commercial maturity yet. In order to make this technology economically viable, two main points which should be considered include decreasing input costs (for cultivation process) and improvement of lipid yield. In an easier word, our ideal is obtaining highest biomass and lipid productivity with lowest cost investment [15].

Current paper aimed to review feasibility for commercialization of microalgal lipid production based on above mentioned points in association with carbon source features. It should be elucidated that in microalgae which are photosynthetic microorganisms, cell growth (biomass productivity), as well as quantity and quality of produced metabolites (like lipids) are extremely affected by carbon metabolism. Accordingly, here we provided a comparative review on microalgal lipid yield under different trophic modes of cultivation, followed by presenting effect of carbon type and concentration on lipid efficiency, and finally discussing on carbon supplementation for large-scale lipid production, as an economical point of view.

\section{Different trophic modes for microalgae cultivation}

\subsection{Photoautotrophy}

All microalgae can utilize inorganic carbon $\left(\mathrm{CO}_{2}\right)$ in the presence of light through photosynthesis. This cultivation strategy, known as photoautotrophy, is the most common mode of microalgae growth [16], particularly in natural ecosystem which cause $\mathrm{CO}_{2}$ sequestration [17]. Carbohydrates generated through $\mathrm{CO}_{2}$ fixation act as energy source to drive metabolic activities [18]. On the other hand, $\mathrm{CO}_{2}$ released by carbohydrates catabolism, can be reutilized during photosynthesis [16]. Indeed, photoautotrophic microalgae transform light to ATP and NADPH, which are consumed for glucose generation in Calvin-Benson cycle. The produced glucose would be a backbone for the other metabolic routes to generate other metabolites like proteins, complex carbohydrates and lipids [19]. Briefly, under photoautotrophic condition microalgae generate organic matters and energy by fixing $\mathrm{CO}_{2}$ as carbon source and sunlight as energy source (Table 1).

Table 1. The characteristics of different trophic modes, merits and demerits

\begin{tabular}{|c|c|c|c|c|}
\hline Trophic mode & Carbon source & Energy & Top advantages & Main disadvantages \\
\hline Photoautotrophy & Inorganic carbon $\left(\mathrm{CO}_{2}\right)$ & Light & $\begin{array}{c}\text { Convenient \& lowcost sources } \\
\mathrm{CO}_{2} \text { sequestration } \\
\text { Low contamination risk }\end{array}$ & $\begin{array}{c}\text { Light-dependency } \\
\text { Low biomass \& lipid productivity } \\
\text { Affected by environmental factors }\end{array}$ \\
\hline Heterotrophy & organic carbon & organic carbon & $\begin{array}{c}\text { Light-independency } \\
\text { Lower harvesting cost } \\
\text { High biomass \& lipid productivity }\end{array}$ & $\begin{array}{l}\text { High cost of carbon source } \\
\text { High contamination risk } \\
\text { Disable to induce photo-dependent } \\
\text { microalgal metabolites }\end{array}$ \\
\hline Mixotrophy & $\begin{array}{l}\text { Inorganic \& organic } \\
\text { carbon }\end{array}$ & $\begin{array}{l}\text { Light \& organic } \\
\text { carbon }\end{array}$ & $\begin{array}{c}\text { Top growth rate } \& \text { high biomass yield } \\
\text { High lipid productivity } \\
\text { Being more prevented against photo } \\
\text { oxidative damage } \\
\text { Lower photoinhibition of substrate uptake } \\
\text { Improved transesterification process due to } \\
\text { lower chlorophyll synthesis (compared to } \\
\text { autotrophy) } \\
\text { More economic than heterotrophy }\end{array}$ & $\begin{array}{l}\text { Limited number of mixotrophic } \\
\text { species } \\
\text { High cost of carbon source } \\
\text { High contamination risk }\end{array}$ \\
\hline Photoheterotrophy & organic carbon & Light & High biomass production & $\begin{array}{l}\text { Low lipid production } \\
\text { High contamination risk } \\
\text { High cost of carbon source }\end{array}$ \\
\hline
\end{tabular}


The main advantage of utilizing photoautotrophic mode for microalgae cultivation is the sequestration of atmospheric $\mathrm{CO}_{2}$ and bypassing its destructive environmental effects [20-22]. However, the ability of microalgae to eliminate $\mathrm{CO}_{2}$ is different and depends on the capacity of Rubisco enzyme for $\mathrm{CO}_{2}$ fixation. Moreover, the essential necessities for microalgae photoautotrophic growth include light, $\mathrm{CO}_{2}$, macro and micro-nutrients. With consider to accessibility of sources, photoautotrophic cultivation for production of biomass has propelled the commercial feasibility of this strategy for many years [23]. As another advantage, the risk of bacterial and fungal contamination is lower than the other trophic modes [15]. Therefore, outdoor cultivation of microalgae in mega-scale (like open pound) is usually set up under photoautotrophic condition.

Light-dependency is the principal drawback of photoautotrophic cultivation mode. In the case of using sun-light for microalgae cultivation in mega-scale, day-night cycles and diurnal variation in light intensity are considered the major problems [24]. Also, the need for high area to volume ratio (A/V) in photobioreactors is another obstacle of this mode. On the other hand, since this cultivation approach is quite photo-dependent, shading effect would be an important limiting factor for algal growth in this way, especially in the case of having a non-adequate mixing system [25].

However, based on its convenience sources, photoautotrophic cultivation strategy seems to be economically viable; low biomass productivity of this approach makes it non-appropriate for trade-scale lipid production. because biomass harvesting cost is increased and the economy of lipid-based products is influenced [26]. In most cases, lipid productivity under photoautotrohic condition has been reported to be lower in comparison to the other nutritional modes [16].

\subsection{Heterotrophy}

In heterotrophic mode of cultivation, cell growth relies on metabolism of organics to provide carbon source and energy. Indeed, organic substrates are responsible to provide energy for metabolic reactions of the microalgae cells as well as carbon skeleton for further biomass production in this trophic mode. Under dark condition, heterotrophic cultivation could be combined with fermentation. Dark metabolism of photosynthetic microalgae is similar to that of non-photosynthetic organisms like bacteria [27].

Some microalgae species, belonging to different taxonomic groups, can survive in dark conditions due to possessing the metabolic plasticity which enables them to absorb and assimilate organic carbon sources [28]. The ability of microalgae to thrive in these conditions mainly depends on biochemical and physiological characteristics of the strain including cell permeability, membrane diffusion, active transport and enzymatic processes [29].

Heterotrophic and photoautotrophic cells are physiologically different in some aspects including the rate of $\mathrm{CO}_{2}$ fixation, carbon incorporation and chlorophyll concentration [18]. Heterotrophic cells exhibit the potential of some morphological variations that enable them to adapt to new metabolic circumstances. Take for instance it's reported that in heterotrophic cells of Tetraselmis suecica, in the case of shifting the energy source from light to carbon source, since no phototropism is needed any longer, flagella disappear [30].

All growth conditions have their own pros and cons (Table 1). Light-independency of heterotrophic cultivation strategy makes it more convenient for photobioreactor design, since high $\mathrm{A} / \mathrm{V}$ ratio is needed in such condition [31]. Moreover, heterotrophy conquers the main problems of photoautotrophic cultivation mode, originated from photodependent factors. High availability of carbon source of density in the cultures as compared photoautotrophic ones. Therefore, higher lipid productivity will be achievable with this nutritional regime [32]. In this line, a $40 \%$ increase in the lipid content of Chlorella protothecoides was achieved after shifting the cultivation mode from photoautotrophy to heterotrophy [33]. The highest lipid productivity of heterotrophic cultures, reported to date, has been about $3700 \mathrm{mg} /$ $\mathrm{L} \cdot \mathrm{day}^{-1}$, belonged to Chlorella [34], while its maximum level under photoautotrophy has been found to be $179 \mathrm{mg} / \mathrm{L} \cdot \mathrm{day}^{-1}$, for Chlorella sp. [35].

Boosting biomass and lipid productivity under heterotrophic condition results in declining the harvesting cost. Accordingly, biomass and lipid productivity by heterotrophic species, under darkness would be more economic than photoautotroph condition since they can run the metabolism in dark and duplicate their biomass [36]. Transition from photoautotrophy toward heterotrophy takes place gradually, and microalgae can adapt their metabolic routes to succeed in new conditions. In this regard, inoculums must possess the organic substrate, and it must be grown in less illumination hours for gradual acclimation to the dark [37].

As a commercial point of view, the cost of media supplementation with organics is the most prominent short fall of heterotrophic mode for large-scale microalgal cultivation [32]. Using carbon-rich wastewater, as an alternative for 
cultivation media including pure organic materials, could be a solution for decreasing production cost. However, increasing the contamination probability by other heterotrophic microorganisms such as bacteria is a certain challenge for these systems. Decontamination will be an additional step which excesses the cost and labor of microalgae culture. As another drawback for heterotrophy, it should be taken into the account that biosynthesis of some valuable metabolites is quite light-dependent; thus such metabolites will not be produced by heterotrophic cultures [28]. On the other hand, photosynthetic oxygen evolution is ceased under dark condition. Diminution of oxygen level is a major parameter negatively affecting the heterotrophically cultivated cells. As an example, low biomass productivity of Chlorella sp. especially in dense cultures was attributed to the oxygen limitation in cultivation media [38].

\subsection{Mixotrophy}

A few numbers of microalgal species, with potential of organic metabolization in the presence of light are able to grow mixotrophically. Mixotrophic microalgae undergo photosynthesis, while they can utilize organics as a source of carbon and energy. It means that mixotrophic microalgae not only could metabolize organic carbons to sustain their growth and accumulate lipids, but also could at the same time assimilate $\mathrm{CO}_{2}$ and produce oxygen through photosynthesis [39].

As a matter of fact, mixotrophy incorporates advantages of heterotrophy and photoautotrophy; and covers the downsides of both strategies. Under mixotrophic condition light energy is not a limiting factor for cell growth and productivity, unlike photoautotrophy [31]. On the other hand, microalgal cells could maintain light-dependent biosynthesis of some valuable products like pigments and carotenoids, unlike heterotrophy [40-41]. Different from heterotrophy, mixotrophic cultivation of microalgae fulfills the aim of $\mathrm{CO}_{2}$-sequestraion somehow.

During the first phase of this model, existing the high content of initial organic carbon in the medium induces heterotrophic condition. When the organic carbon get drained to a certain level, by triggering $\mathrm{CO}_{2}$-fixation, photoautotrophy as second phase will be lunched. In the case of integrating this two-phase mode with dark-light cycle, which allows the growth of autotrophy and heterotrophy under their optimum conditions, the biomass and lipid content of the mixotrophic cultivation will be not merely a sum of autotrophy and heterotrophy [42]. For example, under mixotrophic condition in the presence of $1 \%$ glucose, biomass productivity in Chlamydomonas globose, Chlorella minutissima and Scenedesmus bijuga was found to be respectively 4.9, 6.7 and 5.8 times higher than the photoautotrophically cultured cells [43].

Mixotrophy seems to be a suitable strategy to achieve large amounts of biomass as well as desired metabolites. There are several reports considering the enhanced lipid production in mixotrophic conditions in different microalgae. For example, lipid production by mixotrophic cultures of Tetraselmis sp. KY114885, in the presence of $7.5 \mathrm{~g} / \mathrm{L}$ glucose, was reported to be almost 2.5 times more than that of autotrophic cells [44]. Among different trophic strategies, tested for lipid production by Scenedesmus quadricauda, mixotrophic cultivation, using $5 \mathrm{~g} / \mathrm{L}$ glucose followed by heterotrophic condition, revealed the highest lipid productivity [45], probably due to excess carbon availability. It is suggested that exogenous carbon sources provoke the biosynthesis of fatty acids/carbohydrates. Thus higher lipid production under mixotrophic condition could be related to carbon flux toward glycolytic pathway or acetyl-coA (as a main precursor for fatty acid) biosynthesis [46].

In spite of existing many satisfactory results for lipid production by mixotrophic cultures of microalgae, there are a few reports indicating inadequate lipid productivity in this approach. Namely, as it was reported in Asterarcys sp. SCS1881, lipid content of mixotrophically-grown microalgae was $26.3 \%$ lower than the value measured in photoautotroph condition. The complementary experiments suggested that in this microalgae down-regulation of 3-ketoacyl CoA synthase, the enzyme responsible for fatty acid elongation, under mixotrophy might be the reason for lower lipid accumulation [27].

In aqua ecosystems, mixotrophy is the main form of metabolism, because these ecological habitants consist organic carbon substrates to support homeostatic structure and function of living systems, including microalgae and other organisms [18].

\subsection{Photoheterotrophy}

A few species known as photoorganotrophs (photoheterotroph) can utilize light as energy source and organic 
compounds as carbon source without the requirement to carbon dioxide [47]. Hence, in photoheterotrophic microalgae, both carbon substrates and light are needed at the same time. Even though, photoheterotrophy can enhance metabolite production of some microalgae, it has rarely been conducted in large scale for biofuel production [16]. Similar to heterotrophy and mixotrophy, the limitations of light dependency as a main obstacle to achieve high biomass production especially in large-scale, is prevented in photoheterotrophy [18]. Up to now, little information has been published in literature about using photoheterotrophic cultivation of microalgae for oil production.

\section{Impact of carbon type and concentration on quantity and quality of microalgal lipid production}

\subsection{Various type of organic carbon for media supplementation}

In order to microalgae cultivation trough all described trophic modes except photoautotrophy, the media culture should be included a kind of organic carbon source. Different types of monosaccharides, disaccharides, polyhydric alcohols and organic acids can be utilized to this end. A combination of carbon substrates can also be added to the culture media, as it was shown for $C$. protothecoides which could metabolize the mixture of glucose, glycerol and acetate [48].

The usable type of carbon source depends on some biochemical and physiological parameters of microalgae species. One of most known parameters in this regard is existing the required transport systems within microalgal cell membrane, for uptaking the carbonic substrates. For instance, it is indicated that those microalgae species which have a monocarboxylate transporter, are able to consume acetate from the growth media [49]. As another example, in Chlorella vulgaris an inducible $\mathrm{H}^{+}$/hexose symporter is recognized for uptaking some hexoses from the medium. As is reported, some hexose sugars such as D-glucose, D-fructose, and D-galactose could induce the gene expression of mentioned transporter upon 15 minutes of adding those sugars to media culture. This enables microalgae cells to consume those hexoses as a carbon source. Whereas sucrose, D-mannose, and sugar alcohols could not be uptaken from medium by the cells, as they were not able to induce the symporter gene expression [50]. Interestingly, it was indicated that when GLUT1 gene (encoding a glucose transporter) was introduced to Phaeodactylum tricornutum cells, resulted in changing the metabolism of the microalgae from obligate photoautotrophy to heterotrophy [51].

The type of carbon source, influences on both biomass and lipid productivity of microalgae cultures. However, sometimes may be one kind of carbon source could be the best choice to have the highest biomass yield, while the other type would be the optimum one for lipid production. In this line it was found that, even though glycerol could not increase the biomass production of Haematococcus pluvialis, it upgraded the lipid content of the microalgae as $36.8 \%$ [52]. For Tetraselmis sp. KY 114885, the highest biomass yield and lipid content in mixotrophic condition were achieved in the presence of 5 and $7.5 \mathrm{~g} / \mathrm{L}$ glucose, respectively [10].

\subsection{Carbon source concentration and lipid production}

In addition to the nature of external carbon substrates, their concentrations also affect the growth and biochemistry of microalgae in a species-dependent manner. According to the literatures there is wide range of organic substrates ( 1 to $166 \mathrm{~g} / \mathrm{L}$ ) in which various microalgae species can grow in different trophic modes [53]. The optimum substrate concentration and its effect on biomass is determined by some variables like the type of carbon source, certain speciesspecific features and cultivation conditions. For example, the maximum biomass generation by heterotrophic cultures of T. suecica was obtained in the presence of $5 \mathrm{~g} / \mathrm{L}$ glucose, while the optimum concentration for acetate was only $0.5 \mathrm{~g} / \mathrm{L}$ [30]. On the other hand, even with the same organic substrate, in two different species or strains, the maximum biomass productivity might be achieved in different concentration of the organic. As an example, the best level of glucose for mixotrophic growth of Tetraselmis sp. KY114885 was $5 \mathrm{~g} / \mathrm{L}$ [10], while for Tetraselmis sp. FTC 209, the maximum biomass production was achieved in the presence of $30 \mathrm{~g} / \mathrm{L}$ glucose [54].

For most microalgae species, the optimum required concentration of a certain carbonic substrate is definable. In this line, Harwati et al. [55] found that among studied doses of acetate (7, 70, 140 and $280 \mathrm{mM}$ ), which were added to fresh water, for cultivating Chlorococcum sp. the best dose to fulfill the highest lipid production was $70 \mathrm{mM}$. The 
optimum concentration of glucose for mixotrophic cultivation of marine Chlorella sp. and Nannochloropsis sp., was reported as 20 and $15 \mathrm{~g} / \mathrm{L}$ which increased their lipid production 5.5 and 7.24 times more than that of photoautotrophic cultures, respectively [26].

Similar to carbon type, for carbon content also the optimum case to reach the maximum biomass generation could be different with the optimal one for lipid production. As an example, in mixotrophic cultures of Tetradesmus bernadii the maximum biomass production was achievable through complementing the media with $30 \mathrm{~g} / \mathrm{L}$ glucose, while the best concentration of glucose to obtain highest lipid productivity was $20 \mathrm{~g} / \mathrm{L}$ [56].

Exceeding the concentration of external substrate from a certain level may cause inhibitory effect on cell growth and thus biomass productivity [48]. With increasing glucose concentration from 0 to $10 \mathrm{~g} / \mathrm{L}$, enhanced biomass production for Chlorella sp. and Nannochloropsis sp. was earned; but with raising the dose to $20 \mathrm{~g} / \mathrm{L}$ no improvement was observed [26]. The inhibitory effect of glucose on Chlorella saccharophila, and C. sorokiniana cultures was determined at concentrations of above 25 and $5 \mathrm{~g} / \mathrm{L}$, respectively [57].

Mainly in addition to absolute concentration of carbon, the value of carbon to nitrogen ratio $(\mathrm{C} / \mathrm{N})$ is determinative for potential of microalgae to lipid accumulation. Actually out of a few exceptions, in most microalgae a negative relation between nitrogen concentration and lipid accumulation is recognized [58]. Therefore nitrogen limitation or deprivation is the most prominent strategy to induce hyper-accumulation of lipids. The optimum $\mathrm{C} / \mathrm{N}$ ratio to obtain the highest lipid accumulation depends on species, culture condition and trophic mode. In photoautotrophy the significance this factor on lipid productivity is lower as compared with the other trophic modes.

Table 2. Biomass and lipid productivity of several microalgal strains under different cultivation mode with organic carbon sources or wastewater alternatives

\begin{tabular}{|c|c|c|c|c|c|c|}
\hline Algae & $\begin{array}{l}\text { Cultivation } \\
\text { Mode }\end{array}$ & Substrate $(\mathrm{g} / \mathrm{L})$ & $\begin{array}{l}\text { Maximum } \\
\text { biomass } \\
\text { productivity } \\
\left(\mathrm{mg} / \mathrm{L} \cdot \text { day }^{-1}\right)\end{array}$ & $\begin{array}{l}\text { Maximum lipid } \\
\text { productivity } \\
\left(\mathrm{mg} / \mathrm{L} \cdot \text { day }^{-1}\right)\end{array}$ & Lipid content & reference \\
\hline Chlorella zofingiensis ATCC 30412 & Heterotrophy & 30 Glucose & 692 & 352.92 & $51.1 \%$ & {$[59]$} \\
\hline Chlorella sorokiniana UTEX 1602 & Heterotrophy & 6 Glucose & 463 & 55.56 & $12.63 \%$ & {$[60]$} \\
\hline Chlorella sorokiniana UTEX 1602 & Mixotrophy & 6 Glucose & 761 & 243.52 & $32 \%$ & {$[60]$} \\
\hline Tetraselmis sp. KY114885 & Mixotrophy & 5 Glucose & 102 & 127.08 & $19 \%$ & {$[44]$} \\
\hline Nannochloropsis sp. & Mixotrophy & 10 Glucose & 383 & 74 & $19.3 \%$ & {$[26]$} \\
\hline Coelastrella sp. M-60 & Mixotrophy & 2 Glucose & 70.6 & 12.5 & $17.7 \%$ & {$[61]$} \\
\hline Micractinium sp. M-13 & Mixotrophy & 1 Glucose & 46.8 & 6.8 & $14.5 \%$ & {$[61]$} \\
\hline Chlorella vulgaris & Mixotrophy & 10 Glucose & 254 & 54 & $21 \%$ & {$[62]$} \\
\hline Chlorella vulgaris & Heterotrophy & 10 Glucose & 151 & 35 & $23 \%$ & {$[62]$} \\
\hline Scenedesmus obliquus & Mixotrophy & Glucose & 640 & 270 & $58.3 \%$ & {$[63]$} \\
\hline Dunaliella tertiolecta & Mixotrophy & Carpet wastewater & 38 & 4.6 & $15.2 \%$ & {$[64]$} \\
\hline Chlorella sp. & Mixotrophy & Digested swine & 111 & 30.2 & $27.2 \%$ & {$[65]$} \\
\hline Chlorella protothecoides & Mixotrophy & Municipal wastewater & 382 & 74.4 & $19.6 \%$ & {$[66]$} \\
\hline Chlorella kessleri & Mixotrophy & Municipal wastewater & 400 & 91 & $24.2 \%$ & {$[66]$} \\
\hline
\end{tabular}

\subsection{Effects of carbon source on lipidprofiles}

The kind of trophic mode and the type of carbon source considerably impact on lipid quality in addition to quantity. 
Because the various carbon types could differently regulate the gene expression of the enzymes, involved in fatty acids biosynthesis pathways, and thus modify the fatty acid composition of lipids [59].

There are many reports displaying that carbon supplementation leads to decrease the cumulative percentage of PUFAs but increases the contents of MUFA and SFA [10, 67-69]. The reason is carbon supplementation is followed by upgrading respiration and thus declining free oxygen level. Since oxygen acts as a substrate for desaturase enzyme, its reduction results in up-regulation of saturation process, then raising the percentage of MUFAs and SFAs [70].

Changing in fatty acid composition form PUFA to MUFA and SFA implies shifting from membrane lipids to the reserve ones [71]. While the most of nutritionally important fatty acids belong to PUFA group, the desirable lipid profiles for biodiesel production is a lipid composition in which MUFAs are prominent percentage. Accordingly, the higher capability of heterotrophic and mixotrophic cultures for MUFAs production presents another reason for preference of these trophic modes for biodiesel production, as compared with photoautotrophy [70]. In agreement, there are several reports exhibiting enhanced level of oleic acid, as an (ideal fatty acid for biodiesel production) in mixotrophic cultures. For example, when Tetraselmis sp. KY114885 was grown in mixotrophic condition with glucose, oleic acid constituted more than $50 \%$ of its total fatty acid composition [44]. Similarly, more oleic acid accumulation was detectable in Chlamydomonas reinhardtii under mixotrophy [72].

\section{Sewage instead of media culture: a step towards scaling up of microalgal lipid production}

As is obvious, utilizing synthetic cultivation media (supplemented with organics) for microalgae cultivation, does not have economic justification for industrial lipid production. As an alternative choice, using wastewater and sewage recently has attracted much attention for heterotrophic or mixotrophic cultivation of microalgae [53]. Because wastewater including industrial, agricultural and municipal residues contains remarkable levels of organic carbons and other macro and micronutrients such as nitrogen and phosphorous. In various types of wastewater, due to the variation of chemical composition, microalgae biomass and lipid yield would be different. In agreement, Kamyab et al. [73] displayed that between several types of wastewater, studied for cultivation of $C$. pyrenoidosa, the best lipid yield earned by palm oil mill effluent (POME).

Agricultural residues are the most commonly used wastewater for microalgal biomass production. For instance, heterotrophic cultivation of $C$. protothecoides was accomplished utilizing corn (Zea may) wastewater, which could produce biomass and lipid with a rate of 653 and $361 \mathrm{mg} / \mathrm{L} \times \mathrm{d}$ respectively [33]. Since some agricultural swages contain a mixture of carbohydrates, their effects on improving microalgae growth may be even more pronounced than pure sugars. As an evidence, it was observed that for heterotrophic cultures of Scenedesmus quadricauda, microalgae growth and lipid production in starch wastewater was more than what was earned by pure glucose-included media culture [45]. According to another report, the effects of wheat wastewater on the growth of Scenedesmus obliquus and C. vulgaris were similar to those observed by glucose addition under mixotrophy and heterotrophy [74]. Furthermore, depending on the substrate concentration, soluble product of wheat had a promoting effect on lipid accumulation by mixotrophic cultures of S. obliquus and C. vulgaris [74].

In principal, in order to have an improved microalgae cell growth, it is recommended to hydrolyze agricultural residues prior to usage for cultivation, probably due to the lack of hydrolyzing enzymes in microalgae. For example, lipid productivity of Chlorella vulgaris under photoheterotrophic and mixotrophic condition respectively reached to 42 and $116\left(\mathrm{mg} / \mathrm{L} \cdot \mathrm{day}^{-1}\right)$, when hydrolysate extract of sugarcane (C. protothecoides) was applied for cultivation of microalgae [75].

Municipal and industrial wastewaters can also be considered for cultivation of microalgae. Industrial wastes such as molasses, vinegar, pharmaceutical by-products, and paper mill effluents are some candidates which contain the assimilated low molecular substrates that microalgae can consume [76]. As an instance, glycerol which is the by-product of tans-esterification reaction in biodiesel production process, can be reutilized as an organic source for microalgae and lipid production. Supplementation of media culture with Glycerol under mixotrophic condition caused to $100 \%$ enhancement in lipid productivity of Nannochloropsis sp. as compared to photoautotrophic cultures [77].

By cultivating microalgae in wastewater for biodiesel production, benefiting from biorefinery potential of 
microalgae (for removal of pollutants) would be a side advantage [78-79]. The coupling of biodiesel production and advanced wastewater treatment with immobilized microalgae is a promising approach to commercialization of biodiesel production [80]. Depending the nature of microalgae cultivation, the proper matrix for making immobilized structures would be different. When lipid production is intended, sodium alginate is one of the most recommended materials for making the gel beads [81]. It is proved that in wastewater, immobilized microalgae are more stable than suspended free cells. Not only that, it is frequently reported that biomass and lipid productivity of immobilized microalgae cultures were more than those of free cells [78, 82]. Another merit of utilizing immobilized form of microalgae is the ease of harvesting process, leading to save time and energy, particularly in large scale [83]. Overally, it could be claimed that using immobilization technique to cultivate microalge in wastewater can take microalgal biodiesel production one step closer in achieving the economic feasibility.

\section{Conclusion}

Microalgae is considered as one of the most suitable feedstocks for lipid production. Totally, it could be concluded that among various trophic modes, heterotrophy and mixotrophy are recognized to be the best strategies for biomass generation and lipid (in particular biodiesel) production. Although applying these mentioned trophic modes, using synthetic media culture, is not economically scalable. A recommended approach for commercialization of microalgal lipid production in the industrial-scale is focusing on optimization of immobilized microalgae cultivation in wastewater; which would fulfill a dual function, lipid production and phycoremediation.

\section{References}

[1] Cashore WJ, Sedaghatian MR, Usher RH. Nutritional supplements with intravenously administered lipid, protein hydrolysate, and glucose in small premature infants. Pediatrics. 1975; 56 (1): 8-16.

[2] Hernandez E. Lipids pharmaceutical and cosmetic use. Kirk-Othmer Encyclopedia of Chemical Technology. 2000; $1-19$.

[3] Belsito DV, Hill RA, Klaassen CD, Liebler DC, Marks JJG, Shank RC, et al. Plant-derived fatty acid oils as used in cosmetics. Final Report. 2011; 1-100.

[4] Roy SS, Pal R. Microalgae in aquaculture: A review with special references to nutritional value and fishdietetics, Proceedings of the Zoological Society. Springer; 2015. p.1-8.

[5] Satpati GG. A study on green algal diversity of Indian Sundarbans mangrove forest as potential source of Biodiesel. Available from: http://hdl.handle.net/10603/172166.

[6] Satpati GG, Gorain PC, Paul I, Pal R. An integrated salinity-driven workflow for rapid lipid enhancement in green microalgae for biodiesel application. RSC advances. 2016; 6(113): 112340-112355.

[7] Khosravitabar F. Microalgal biohydrogen photoproduction: Scaling up challenges and the ways forward. Journal of Applied Phycology. 2020; 32: 277-289.

[8] Peng L, Fu D, Chu H, Wang Z, Qi H. Biofuel production from microalgae: A review. Environmental Chemistry Letters. 2020; 18: 285-297.

[9] Borowitzka MA. The 'stress' concept in microalgal biology-homeostasis, acclimation and adaptation. Journal of Applied Phycology. 2018; 30(5): 2815-2825.

[10] Lari Z, Moradi-Kheibari N, Ahmadzadeh H, Abrishamchi P, Moheimani NR, Murry MA. Bioprocess engineering of microalgae to optimize lipid production through nutrient management. Journal of Applied Phycology. 2016; 28(6): 3235-3250.

[11] Delucchi M. A lifecycle emissions model (LEM): Lifecycle emissions from transportation fuels, motor vehicles, transportation modes, electricity use, heating and cooking fuels, and materials. UC Davis Institute of Transportation Studies; 2003.

[12] Khosravitabar F, Hippler M. A new approach for improving microalgal biohydrogen photoproduction based on safe \& fast oxygen consumption. International Journal of Hydrogen Energy. 2019; 44 (33): 17835-17844.

[13] Kamyab H, Chelliapan S, Din MFM, Shahbazian-Yassar R, Rezania S, Khademi T, et al. Evaluation of Lemna minor and Chlamydomonas to treat palm oil mill effluent and fertilizer production. Journal of Water Process Engineering. 2017; 17: 229-236. 
[14] Wang B, Li Y, Wu N, Lan CQ. $\mathrm{CO}_{2}$ bio-mitigation using microalgae. Applied Microbiology and Biotechnology. 2008; 79(5): 707-718.

[15] Yin Z, Zhu L, Li S, Hu T, Chu R, Mo F, et al. A comprehensive review on cultivation and harvesting of microalgae for biodiesel production: Environmental pollution control and future directions. Bioresource Technology. 2020; 301: 122804.

[16] Chen C-Y, Yeh K-L, Aisyah R, Lee D-J, Chang J-S. Cultivation, photobioreactor design and harvesting of microalgae for biodiesel production: A critical review. Bioresource Technology. 2011; 102(1): 71-81.

[17] Gorain PC, Sengupta S, Satpati GG, Paul I, Tripathi S, Pal R. Carbon sequestration in macroalgal mats of brackishwater habitats in Indian Sunderbans: Potential as renewable organic resource. Science of the Total Environment. 2018; 626: 689-702.

[18] Mohan SV, Devi MP, Subhash GV, Chandra R. Chapter 8-algae oils as fuels. Biofuels from Algae. Elsevier: Amsterdam; 2014. p.155-187.

[19] Suali E, Sarbatly R. Conversion of microalgae to biofuel. Renewable and Sustainable Energy Reviews. 2012; 16(6): 4316-4342.

[20] Aishvarya V, Pradhan N, Nayak R, Sukla L, Mishra B. Enhanced inorganic carbon uptake by Chlorella sp. IMMTCC-2 under autotrophic conditions for lipid production and $\mathrm{CO}_{2}$ sequestration. Journal of Applied Phycology. 2012; 24 (6); 1455-1463.

[21] Sundarrajan P, Gopinath KP, Greetham D, Antonysamy AJ. A review on cleaner production of biofuel feed stock from integrated $\mathrm{CO}_{2}$ sequestration and wastewater treatment system. Journal of Cleaner Production. 2019; 210: 445-458.

[22] Kurano N, Ikemoto H, Miyashita H, Hasegawa T, Hata H, Miyachi S. Fixation and utilization of carbon dioxide by microalgal photosynthesis. Energy Conversion and Management. 1995; 36(6): 689-692.

[23] Lowrey J, Brooks MS, Mcginn PJ. Heterotrophic and mixotrophic cultivation of microalgae for biodiesel production in agricultural wastewaters and associated challenges-A critical review. Journal of Applied Phycology 2015; 27(4): 1485-1498.

[24] Kitajima Y, El-Shishtawy RM, Ueno Y, Otsuka S, Miyake J, Morimoto M. Analysis of compensation point of light using plane-type photosynthetic bioreactor. BioHydrogen. Springer; 1998. p.359-367.

[25] Sakthivel R, Elumalai S, Arif MM. Microalgae lipid research, past, present: a critical review for biodiesel production, in the future. Journal of Experimental Sciences. 2011; 2(10): 29-49.

[26] Cheirsilp B, Torpee S. Enhanced growth and lipid production of microalgae under mixotrophic culture condition: effect of light intensity, glucose concentration and fed-batch cultivation. Bioresource Technology. 2012; 110: 510516.

[27] Li T, Yang F, Xu J, Wu H, Mo J, Dai L, et al. Evaluating differences in growth, photosynthetic efficiency, and transcriptome of Asterarcys sp. SCS-1881 under autotrophic, mixotrophic, and heterotrophic culturing conditions. Algal Research. 2020; 45: 101753.

[28] Perez-Garcia O, Escalante FME, De-Bashan LE, Bashan Y. Heterotrophic cultures of microalgae: Metabolism and potential products. Water Research. 2011; 45(1): 11-36.

[29] Garcıa MC, Mirón AS, Sevilla JF, Grima EM, Camacho FG. Mixotrophic growth of the microalga Phaeodactylum tricornutum: influence of different nitrogen and organic carbon sources on productivity and biomass composition. Process Biochemistry. 2005; 40(1): 297-305.

[30] Azma M, Mohamad R, Rahim RA, Ariff AB. Improved protocol for the preparation of Tetraselmis suecica axenic culture and adaptation to heterotrophic cultivation. The Open Biotechnology Journal. 2010; 4: 36-46.

[31] Brennan L, Owende P. Biofuels from microalgae-A review of technologies for production, processing, and extractions of biofuels and co-products. Renewable and Sustainable Energy Reviews. 2010; 14(2): 557-577.

[32] Amaro HM, Guedes AC, Malcata FX. Advances and perspectives in using microalgae to produce biodiesel. Applied Energy. 2011; 88(10): 3402-3410.

[33] Xu H, Miao X, Wu Q. High quality biodiesel production from a microalga Chlorella protothecoides by heterotrophic growth in fermenters. Journal of Biotechnology. 2006; 126(4): 499-507.

[34] Xiong W, Liu L, Wu C, Yang C, Wu Q. 13C-tracer and gas chromatography-mass spectrometry analyses reveal metabolic flux distribution in the oleaginous microalga Chlorella protothecoides. Plant Physiology. 2010; 154(2): 1001-1011.

[35] Chiu SY, Kao CY, Chen CH, Kuan TC, Ong SC, Lin CS. Reduction of $\mathrm{CO}_{2}$ by a high-density culture of Chlorella sp. in a semicontinuous photobioreactor. Bioresource Technology. 2008; 99(9): 3389-3396.

[36] Perez-Garcia O, Escalante FM, De-Bashan LE, Bashan Y. Heterotrophic cultures of microalgae: Metabolism and 
potential products. Water Research. 2011; 45(1): 11-36.

[37] Azma M, Mohamad R, Rahim RA, Ariff AB. Improved protocol for the preparation of Tetraselmis suecica axenic culture and adaptation to heterotrophic cultivation. The Open Biotechnology Journal. 2010; 4(1): 36-46.

[38] Wu Z, Shi X. Optimization for high-density cultivation of heterotrophic Chlorella based on a hybrid neural network model. Letters in Applied Microbiology. 2007; 44 (1): 13-18.

[39] Kong WB, Song H, Hua SF, Yang H, Yang Q, Xia CG. Enhancement of biomass and hydrocarbon productivities of Botryococcus braunii by mixotrophic cultivation and its application in brewery wastewater treatment. African Journal of Microbiology Research. 2012; 6(7): 1489-1496.

[40] Xie Y, Li J, Ma R, Ho SH, Shi X, Liu L, et al. Bioprocess operation strategies with mixotrophy/photoinduction to enhance lutein production of microalga Chlorella sorokiniana FZU60. Bioresource Technology. 2019; 290: 121798.

[41] Menegol T, Romero-Villegas G, López-Rodríguez M, Navarro-López E, López-Rosales L, Chisti Y, etal. Mixotrophic production of polyunsaturated fatty acids and carotenoids by the microalga Nannochloropsis gaditana. Journal of Applied Phycology. 2019; 31(5): 2823-2832.

[42] Chen CY, Liu CC. Optimization of lutein production with a two-stage mixotrophic cultivation system with Chlorella sorokiniana MB-1. Bioresource Technology. 2018; 262; 74-79.

[43] Bhatnagar A, Chinnasamy S, Singh M, Das K. Renewable biomass production by mixotrophic algae in the presence of various carbon sources and wastewaters. Applied Energy. 2011; 88(10): 3425-3431.

[44] Lari Z, Abrishamchi P, Ahmadzadeh H, Soltani N. Differential carbon partitioning and fatty acid composition in mixotrophic and autotrophic cultures of a new marine isolate Tetraselmis sp. KY114885. Journal of Applied Phycology. 2019; 31(1): 201-210.

[45] Zhao G, Yu J, Jiang F, Zhang X, Tan T. The effect of different trophic modes on lipid accumulation of Scenedesmus quadricauda. Bioresource Technology. 2012; 114: 466-471.

[46] Jia J, Han D, Gerken HG, Li Y, Sommerfeld M, Hu Q, et al. Molecular mechanisms for photosynthetic carbon partitioning into storage neutral lipids in Nannochloropsis oceanica under nitrogen-depletion conditions. Algal Research. 2015; 7: 66-77.

[47] Frac M, Jezierska-Tys S, Tys J. Microalgae for biofuels production and environmental applications: A review. African Journal of Biotechnology. 2010; 9(54): 9227-9236.

[48] Heredia-Arroyo T, Wei W, Hu B. Oil accumulation via heterotrophic/mixotrophic Chlorella protothecoides. Applied Biochemistry and Biotechnology. 2010; 162(7): 1978-1995.

[49] Zhang C, Zhang L, Liu J. Exogenous sodium acetate enhances astaxanthin accumulation and photoprotection in Haematococcus pluvialis at the non-motile stage. Journal of Applied Phycology. 2019; 31(2): 1001-1008.

[50] Komor E, Schobert C, Cho BH. Sugar specificity and sugar-proton interaction for the hexose-proton-symport system of Chlorella. European Journal of Biochemistry. 1985; 146(3): 649-656.

[51] Zaslavskaia L, Lippmeier J, Shih C, Ehrhardt D, Grossman A, Apt K. Trophic conversion of an obligate photoautotrophic organism through metabolic engineering. Science. 2001; 292(5524): 2073-2075.

[52] Zhang L, Zhang C, Liu J, Yang N. A strategy for stimulating astaxanthin and lipid production in Haematococcus pluvialis by exogenous glycerol application under low light. Algal Research. 2020; 46: 101779.

[53] Schmidt RA, Wiebe MG, Eriksen NT. Heterotrophic high cell-density fed-batch cultures of the phycocyaninproducing red alga Galdieria sulphuraria. Biotechnology and Bioengineering. 2005; 90(1): 77-84.

[54] Mohamed MS, Tan JS, Kadkhodaei S, Mohamad R, Mokhtar MN, Ariff AB. Kinetics and modeling of microalga Tetraselmis sp. FTC 209 growth with respect to its adaptation toward different trophic conditions. Biochemical Engineering Journal. 2014; 88: 30-41.

[55] Harwati TU, Willke T, Vorlop KD. Characterization of the lipid accumulation in a tropical freshwater microalgae Chlorococcum sp. Bioresource Technology. 2012; 121: 54-60.

[56] Gao B, Huang L, Wang F, Chen A, Zhang C. Bilateral and simultaneous accumulation of lipid and biomass in the novel oleaginous green microalga Tetradesmus bernardii under mixotrophic growth. Algalresearch. 2019; 37: 6473.

[57] Tan C, Johns M. Fatty acid production by heterotrophic Chlorella saccharophila. Hydrobiologia. 1991; 215(1): 13-19.

[58] Lari Z, Moradi-Kheibari N, Ahmadzadeh H, Abrishamchi P, Moheimani NR, Murry MA. Bioprocess engineering of microalgae to optimize lipid production through nutrient management. Journal of Applied Phycology. 2016; 28: $3235-3250$.

[59] Liu J, Huang J, Sun Z, Zhong Y, Jiang Y, Chen F. Differential lipid and fatty acid profiles of photoautotrophic and heterotrophic Chlorella zofingiensis: Assessment of algal oils for biodiesel production. Bioresource Technology. 2011; 102(1): 106-110. 
[60] Li T, Zheng Y, Yu L, Chen S. Mixotrophic cultivation of a Chlorella sorokiniana strain for enhanced biomass andlipid production. Biomass and Bioenergy. 2014; 66: 204-213.

[61] Karpagam R, Raj KJ, Ashokkumar B, Varalakshmi P. Characterization and fatty acid profiling in two fresh water microalgae for biodiesel production: Lipid enhancement methods and media optimization using response surface methodology. Bioresource Technology. 2015; 188: 177-184.

[62] Liang Y, Sarkany N, Cui Y. Biomass and lipid productivities of Chlorella vulgaris under autotrophic, heterotrophic and mixotrophic growth conditions. Biotechnology Letters. 2009; 31(7): 1043-1049.

[63] Mandal S, Mallick N. Microalga Scenedesmus obliquus as a potential source for biodiesel production. Applied Microbiology and Biotechnology. 2009; 84(2): 281-291.

[64] Chinnasamy S, Bhatnagar A, Hunt RW, Das K. Microalgae cultivation in a wastewater dominated by carpet mill effluents for biofuel applications. Bioresource Technology. 2010; 101(9): 3097-3105.

[65] Hu B, Zhou W, Min M, Du Z, Chen P, Ma X, et al. Development of an effective acidogenically digested swine manure-based algal system for improved wastewater treatment and biofuel and feed production. Applied Energy. 2013; 107: 255-263.

[66] Li Y, Zhou W, Hu B, Min M, Chen P, Ruan RR. Effect of light intensity on algal biomass accumulation and biodiesel production for mixotrophic strains Chlorella kessleri and Chlorella protothecoide cultivated in highly concentrated municipal wastewater. Biotechnology and Bioengineering. 2012; 109(9): 2222-2229.

[67] Garcí MC, Sevilla JF, Fernández FA, Grima EM, Camacho FG. Mixotrophic growth of Phaeodactylum tricornutum on glycerol: growth rate and fatty acid profile. Journal of Applied Phycology. 2000; 12(3-5): 239-248.

[68] Wang H, Fu R, Pei G. A study on lipid production of the mixotrophic microalgae Phaeodactylum tricornutum on various carbon sources. Afr J Microbiol Res. 2012; 6(5): 1041-1047.

[69] Veloza AJ, Chu FLE, Tang KW. Trophic modification of essential fatty acids by heterotrophic protists and its effects on the fatty acid composition of the copepod Acartia tonsa. Marine Biology. 2006; 148(4): 779-788.

[70] Atabani AE, Silitonga AS, Badruddin IA, Mahlia T, Masjuki H, Mekhilef S. A comprehensive review on biodiesel as an alternative energy resource and its characteristics. Renewable and Sustainable Energy Reviews. 2012; 16(4): 2070-2093.

[71] Smith JP, Hughes A, Mcevoy L, Day J. Tailoring of the biochemical profiles of microalgae by employing mixotrophic cultivation. Bioresource Technology Reports. 2020; 9: 100321.

[72] Smith RT, Gilmour DJ. The influence of exogenous organic carbon assimilation and photoperiod on the carbon and lipid metabolism of Chlamydomonas reinhardtii. Algal Research. 2018; 31: 122-137.

[73] Kamyab H, Chelliapan S, Lee CT, Khademi T, Kumar A, Yadav KK, et al. Improved production of lipid contents by cultivating Chlorella pyrenoidosa in heterogeneous organic substrates. Clean Technologies and Environmental Policy. 2019; 21(10): 1969-1978.

[74] El-Sheekh M, Bedaiwy M, Osman M, Ismail M. Mixotrophic and heterotrophic growth of some microalgae using extract of fungal-treated wheat bran. Int J Recycl Org Waste Agricult. 2012; 1(1): 1-9.

[75] Zheng H, Gao Z, Yin F, Ji X, Huang H. Lipid production of Chlorella vulgaris from lipid-extracted microalgal biomass residues through two-step enzymatic hydrolysis. Bioresource technology. 2012; 117: 1-6.

[76] Perez-Garcia O, Bashan Y, Esther Puente M. Organic carbon supplementation of sterilized municipal wastewater is essential for heterotrophic growth and removing ammonium by the microalga Chlorella vulgaris 1 . Journal of Phycology. 2011; 47(1): 190-199.

[77] Das P, Lei W, Aziz SS, Obbard JP. Enhanced algae growth in both phototrophic and mixotrophic culture under blue light. Bioresource Technology. 2011; 102(4): 3883-3887.

[78] Katam K, Bhattacharyya D. Simultaneous treatment of domestic wastewater and bio-lipid synthesis using immobilized and suspended cultures of microalgae and activated sludge. Journal of Industrial and Engineering Chemistry. 2019; 69: 295-303.

[79] Kamyab H, Din MFM, Keyvanfar A, Majid MZA, Talaiekhozani A, Shafaghat A, et al. Efficiency of microalgae Chlamydomonas on the removal of pollutants from palm oil mill effluent (POME). Energy Procedia. 2015; 75: 2400-2408.

[80] Wang PT, Zhang JJ, Li ZY, Bai J. Life Cycle Energy Analysis and Biodiesel Production Potential Evaluation for Immobilized Microalgae Cultivated with Secondary Effluent in China, New Energy and Sustainable Development. Proceedings of 2016 International Conference on New Energy and Sustainable Development. World Scientific; 2017. p.568-576.

[81] Emparan Q, Jye YS, Danquah MK, Harun R. Cultivation of Nannochloropsis sp. microalgae in palm oil mill effluent (POME) media for phycoremediation and biomass production: Effect of microalgae cells with and without 
beads. Journal of Water Process Engineering. 2020; 33: 101043.

[82] Rushan NH, Yasin NHM, Sepian NRA, Said FM, Shafei NI. Effect of immobilization method on the growth of chlorella vulgaris and fatty acid profile for biodiesel production. Indonesian Journal of Chemistry. 2019; 19(3): 767-776.

[83] Ameri M, Khavari-Nejad R, Soltani N, Najafi F, Bagheri A. Application of immobilized microalgaefor native wastewater treatment. International Journal on Algae. 2020; 22(1). 